\title{
A bússola investigativa: mapeando estudos sobre projetos investigativos nos anos iniciais
}

\author{
The investigative compass: mapping studies on investigative projects \\ in the early years
}

\section{La brújula investigadora: mapeo de estudios sobre proyectos investigadores en los primeros años}

Patrícia Costa ${ }^{1}$; Charles Guidotti ${ }^{2}$

\section{RESUMO}

Apresentamos neste artigo uma revisão bibliográfica, do tipo estado da arte, que objetivou mapear dissertações produzidas entre os anos de 2010 e 2019, abrangendo a temática "Ensino de Ciências, por investigação, nos anos iniciais do Ensino Fundamental". Para isso, optou-se por analisar estudos desenvolvidos em programas profissionais de pós-graduação na área da Educação em Ciências e Matemática. Iniciamos apresentando os aspectos metodológicos desta pesquisa, os programas profissionais de pós-graduação encontrados e a seleção dos trabalhos que versam ao propósito deste estudo. A partir da análise dos dados, classificamos e descrevemos as dissertações selecionadas. Os aspectos emergentes encontrados na análise demonstram que o ensino por investigação acontece de forma colaborativa e dialógica num cenário em que professores e estudantes articulam os conhecimentos científicos com contexto social, a partir de situações-problemas. Oportuniza a experimentação, o levantar hipóteses e o desenvolvimento de novas possibilidades de pensar e agir.

Palavras-chave: Revisão bibliográfica; Projetos Investigativos; Ensino de Ciências; Anos Iniciais do Ensino Fundamental.

\begin{abstract}
In this article, we present a bibliographic review, of the state-of-the-art type, which aimed to map dissertations produced between the years 2010 and 2019, covering the theme "Science teaching by research in the early years of Elementary Education". For this, we chose to analyze studies developed in professional graduate programs in the field of Education in Science and Mathematics. We begin by presenting the methodological aspects of the research, the programs found and the selection of works that address the purpose of this study. From the data analysis, we've classified and described the selected dissertations. The emerging aspects found in the analysis demonstrate that teaching by research takes place in a collaborative and dialogical way in a scenario which teachers and students articulate scientific knowledge with a social context, based on problem situations. It provides opportunities for experimentation, raising hypotheses and developing new possibilities for thinking and acting.
\end{abstract}

\footnotetext{
${ }^{1}$ Estudante do Programa de Pós-Graduação em Ensino de Ciências Exatas pela Universidade Federal do Rio Grande (FURG), campus Santo Antônio da Patrulha, Santo Antônio da Patrulha, Rio Grande do Sul, Brasil. Integrante do grupo de pesquisa Comunidade de Indagação em Ensino de Física Interdisciplinar (CIEFI). Email: patriciaulbra@hotmail.com

${ }^{2}$ Doutor em Educação em Ciências pela Universidade Federal do Rio Grande (FURG). Professor adjunto no Instituto de Matemática, Estatística e Física da FURG, campus Santo Antônio da Patrulha, Santo Antônio da Patrulha, Rio Grande do Sul, Brasil. Integrante do grupo de pesquisa Comunidade de Indagação em Ensino de Física Interdisciplinar (CIEFI). E-mail: charles.guidotti@furg.br
} 
Keywords: Bibliographic review, Research projects, Science teaching, Early years of Elementary Education.

\section{RESUMEN}

Presentamos en este artículo una revisión bibliográfica, como estado del arte, donde su objetivo es mapear las disertaciones producidas entre los años de 2010 y 2019, abarcando la temática "Enseñanza de la Ciencia mediante investigación en los primeros años de la Escuela Primária". Para eso, se decidió analizar estudios desarrollados en los programas profesionales de la pós-graduación en el campo de la Educación en Ciencias y Matemática. Empezamos presentando los aspectos metodológicos de la investigación, los programas encontrados y la selección de las obras que abordan el propósito de este estudio. A partir del análisis de los dat os, clasificamos y describimos las disertaciones seleccionadas. Los aspectos emergentes encontrados en el análisis demuestran que la enseñanza por la investigación ocurre de manera colaborativa y dialógica en un escenário en el que docentes y estudiantes articulan los conocimientos científicos con un contexto social, a partir de situaciones-problemáticas. Proporciona experimentación, o plantear hipótesis y se desarollan nuevas posibilidades de pensar y actuar.

Palabras clave: Revisión bibliográfica; Proyectos de investigación; Enseñanza de las Ciencias; Primeros años de la escuela primaria.

\section{INTRODUÇÃO}

A promoção do ensino de Ciências por investigação não é recente. O estudo desenvolvido por Guidotti e Heckler (2017) apresenta diferentes concepções associadas à investigação em sala de aula, registradas a partir do século XIX em documentos oficiais publicados nos Estados Unidos da América e no Brasil. De acordo com os autores, a partir de demandas educacionais mobilizadas ao longo do tempo, emergiram inúmeros entendimentos acerca da investigação enquanto abordagem de ensino em sala de aula. Com isso, encontramos na literatura diferentes denominações que remetem à investigação como estratégia didático-pedagógica, tais como: atividades investigativas, resolução de problemas, ensino por descoberta, aprendizagem por projetos, ensino por investigação, entre outras.

Em linhas gerais, a investigação em sala de aula é assumida neste artigo como uma abordagem de ensino que possibilita transformações nas formas de ensinar e aprender Ciências. Assim, utilizaremos o termo projetos investigativos, embasado nos estudos de Guidotti e Heckler (2017; 2019; 2020), pautado nas ações em que professores e estudantes desenvolvem de forma colaborativa observações, indagações, construção e comunicação de argumentos.

A investigação em sala de aula oportuniza aos estudantes, além do aprender Ciências, inseri-los na cultura da produção do conhecimento científico. Além disso, permite aos estudantes compreender, tanto os métodos de investigação quanto as dinâmicas sociais que caracterizam as Ciências como empreendimento cultural e social (CARVALHO, 2004).

Considerando esses aspectos, desenvolvemos uma revisão bibliográfica, do tipo estado da arte, com o objetivo de mapear dissertações desenvolvidas em programas profissionais de formação de professores de Ciências e Matemática, que versem sobre o ensino de Ciências por investigação nos anos iniciais do Ensino Fundamental. 
Conforme Romanowski e Ens (2006), realizar pesquisas denominadas estado da arte promove motivação pela capacidade de aprofundar estudos que abrangem a mesma temática. Neste cenário, mapeiam-se as tendências e os caminhos que se tenha considerado sobre o tema de pesquisa. Essas ações potencializam a cooperação na organização e investigação de uma determinada área do conhecimento. As autoras destacam que:

Estados da arte podem significar uma contribuição importante na constituição do campo teórico de uma área de conhecimento, pois procuram identificar os aportes significativos da construção da teoria e prática pedagógica, apontar as restrições sobre o campo em que se move a pesquisa, as suas lacunas de disseminação, identificar experiências inovadoras investigadas que apontem alternativas de solução para os problemas da prática e reconhecer as contribuições da pesquisa na constituição de propostas na área focalizada (ROMANOWSKI e ENS, 2006, p. 39).

Ferreira (2002) enfatiza que as pesquisas intituladas estado da arte movem os pesquisadores pelo desafio de descobrirem o que se tem estudado. A autora argumenta que essas pesquisas "são reconhecidas por realizarem uma metodologia de caráter inventariante e descritiva da produção acadêmica e científica, sobre o tema que busca investigar a luz de categorias e facetas" (Ibidem, 2002, p. 258).

A contar deste entendimento, visamos investigar e divulgar produções acadêmicas desenvolvidas sobre o ensino de Ciências por investigação nos anos iniciais do Ensino Fundamental. Para tal fim, a escrita deste artigo está dividida em três partes. Na primeira realizamos a descrição metodológica da pesquisa, apresentamos os programas profissionais de pós-graduação encontrados e a seleção dos trabalhos que versam sobre o tema em estudo. Na segunda parte elaboramos a análise quantitativa das dissertações que se referem, especificamente, às palavras-chave correlatas ao trabalho. $E$, por fim, descrevemos as dissertações selecionadas.

\section{ASPECTOS METODOLÓGICOS}

Segundo Ferreira (2002), para realizar o estado da arte é utilizado como fonte de análise, catálogos das instituições de Ensino Superior e as bibliotecas virtuais, "associações nacionais e órgãos de fomento da pesquisa" (FERREIRA, 2002, p. 258). Para tanto optamos por analisar os estudos desenvolvidos em programas profissionais do campo da Educação com enfoque na formação de professores de Ciências e Matemática, Ensino de Ciências Naturais e Matemática, Ensino de Física, Ensino de Ciências Humanas, Sociais e da Natureza e Formação Científica, Educacional, Tecnológica e correlatos. Assim, para a produção de dados realizamos o mapeamento de dissertações publicadas no período de 2010 a 2019. Selecionamos estudos produzidos no âmbito de programas profissionais de pós-graduação de formação de professores de Ciências e Matemática. Realizamos a revisão bibliográfica, do tipo estado da arte, mapeando os principais resultados, as características dos produtos educacionais produzidos, destacando aspectos teórico-práticos que possam contribuir para a construção deste artigo.

Para identificar os programas profissionais de pós-graduação pertencentes ao campo do Ensino de Ciências e Matemática, utilizamos a plataforma Sucupira. Desse modo encontramos quarenta e cinco programas, os quais estão indicados no quadro 1. 
Quadro 1 - Instituições e programas de mestrados profissionais nas áreas do Ensino de Ciências e Matemática

\begin{tabular}{|c|c|c|}
\hline & Instituição de ensino (RIs) & Programas de Pós-Graduação \\
\hline 1. & $\begin{array}{l}\text { Instituto Federal de Educação, Ciência e } \\
\text { Tecnologia Sul-Rio-Grandense }\end{array}$ & $\begin{array}{l}\text { Ciências e Tecnologias na Educação (MPET- } \\
\text { PPGEdu) }\end{array}$ \\
\hline 2. & Universidade Federal do Pará & $\begin{array}{l}\text { Docência em Educação em Ciências e } \\
\text { Matemáticas (PPGDOC) }\end{array}$ \\
\hline 3 & Universidade Estadual de Mato Grosso do Sul & Educação Científica e Matemática (PROFECM) \\
\hline 4. & $\begin{array}{l}\text { Instituto Federal de Educação, Ciência e } \\
\text { Tecnologia do Espírito Santo }\end{array}$ & $\begin{array}{l}\text { Educação em Ciências e Matemática } \\
\text { (PPGEDUCIMAT) }\end{array}$ \\
\hline 5. & $\begin{array}{l}\text { Universidade Federal dos Vales do } \\
\text { Jequitinhonha e Mucuri }\end{array}$ & $\begin{array}{l}\text { Educação em Ciências, Matemática e Tecnologia } \\
\text { (PPGECMaT) }\end{array}$ \\
\hline 6. & Universidade Federal de Juiz de Fora & Educação Matemática (PPGEM) \\
\hline 7. & $\begin{array}{l}\text { Instituto Federal de Educação, Ciência e } \\
\text { Tecnologia de Goiás }\end{array}$ & Educação para Ciências e Matemática (PPGECM) \\
\hline 8. & Pontifícia Universidade Católica de Minas Gerais & Ensino (PPGE) \\
\hline 9. & $\begin{array}{l}\text { Universidade Regional Integrada do Alto } \\
\text { Uruguai e das Missões }\end{array}$ & Ensino Científico e Tecnológico (PPGEnCT) \\
\hline 10. & Universidade de Brasília & Ensino de Ciências (PPGEC) \\
\hline 11. & $\begin{array}{l}\text { Fundação Universidade Federal de Mato Grosso } \\
\text { do Sul }\end{array}$ & Ensino de Ciências (PPEC) \\
\hline 12. & Universidade Federal de Ouro Preto & Ensino de Ciências (MPEC) \\
\hline 13. & Fundação Universidade Federal do Pampa & Ensino de Ciências (PPGEC) \\
\hline 14. & Universidade Estadual de Roraima & Ensino de Ciências (PPGEC) \\
\hline 15. & Universidade Estadual de Goiás & Ensino de Ciências (PPEC) \\
\hline 16. & Universidade Federal de Mato Grosso & Ensino de Ciências Naturais (PPGECN) \\
\hline 17. & Universidade Estadual da Paraíba & Ensino de Ciências e Matemática (PPGECM) \\
\hline 18. & Universidade Federal do Ceará & Ensino de Ciências e Matemática (PPGENCIMA) \\
\hline 19. & Universidade Federal de Pelotas & Ensino de Ciências e Matemática (PPGECM) \\
\hline 20. & Universidade Cruzeiro do Sul & Ensino de Ciências e Matemática (PPGECM) \\
\hline 21. & Universidade Federal de Uberlândia & Ensino de Ciências e Matemática (PPGECM) \\
\hline 22. & Universidade Federal de Alagoas & Ensino de Ciências e Matemática (PPGECIM) \\
\hline 23. & Universidade de Caxias do Sul & Ensino de Ciências e Matemática (PPGECIMA) \\
\hline 24. & Universidade Federal do Acre & Ensino de Ciências e Matemática (MPECIM) \\
\hline 25. & $\begin{array}{l}\text { Instituto Federal de Educação, Ciência e } \\
\text { Tecnologia de São Paulo }\end{array}$ & Ensino de Ciências e Matemática (PPGENCIMA) \\
\hline 26. & Universidade Franciscana & Ensino de Ciências e Matemática (PPGECIMAT) \\
\hline 27. & Fundação Universidade de Passo Fundo & Ensino de Ciências e Matemática (PPGECM) \\
\hline 28. & Universidade Federal do Rio Grande & Ensino de Ciências Exatas (PPGECE) \\
\hline 29. & $\begin{array}{l}\text { Fundação Vale do Taquari de Educação e } \\
\text { Desenvolvimento Social }\end{array}$ & Ensino de Ciências Exatas (PPGECE) \\
\hline 30. & Universidade Federal do Rio Grande do Norte & $\begin{array}{l}\text { Ensino de Ciências Naturais e Matemática } \\
\text { (PPGECNM) }\end{array}$ \\
\hline 31. & Universidade Estadual do Centro-Oeste & $\begin{array}{l}\text { Ensino de Ciências Naturais e Matemática } \\
\text { (PPGEn) }\end{array}$ \\
\hline
\end{tabular}




\begin{tabular}{||l|l||l||}
\hline 32. & Universidade Federal do Rio de Janeiro & Ensino de Física (PPGEF) \\
\hline \hline 33. & Universidade Federal do Rio Grande do Sul & $\begin{array}{l}\text { Ensino de Física (PPGEF) } \\
\text { Ensino de Matemática (PPGEMAT) }\end{array}$ \\
\hline \hline 34. & Universidade Federal do Espírito Santo & $\begin{array}{l}\text { Ensino de Física (PPGEnFis) } \\
\text { Ensino na Educação Básica (PPGEEB) }\end{array}$ \\
\hline \hline 35. & Universidade Tecnológica Federal do Paraná & $\begin{array}{l}\text { Ensino de Ciência e Tecnologia (PPGECT) } \\
\text { Ensino de Matemática (PPGEM) } \\
\text { Formação Científica, Educacional e Tecnológica } \\
\text { (PPGFCET) } \\
\text { Ciências Humanas, Sociais e da Natureza } \\
\text { (PPGEN) }\end{array}$ \\
\hline \hline 36. & Universidade Federal de São Paulo & Ensino em Ciências da Saúde (PPGECS) \\
\hline 37. & Universidade Estadual do Rio Grande do Sul & $\begin{array}{l}\text { Formação Docente para Ciências, Tecnologias, } \\
\text { Engenharias e Matemática (PPGSTEM) }\end{array}$ \\
\hline \hline 38. & Colégio Pedro II & Práticas de Educação Básica (MPPEB) \\
\hline \hline 39. & Universidade Federal do ABC & Ensino de Física (MNPEF) \\
\hline \hline 40. & Universidade Federal de Minas Gerais & Educação e Docência (PROMESTRE) \\
\hline \hline 41. & Universidade de São Paulo & Projetos Educacionais de Ciências (PPGE) \\
\hline \hline & TOTAL & 45 programas de MP \\
\hline \hline
\end{tabular}

Fonte: Costa; Guidotti (2020)

No site dos programas procuramos nos títulos e resumos das dissertações os seguintes indicadores: anos iniciais, Ensino Fundamental, ensino por investigação, abordagens investigativas e ensino de Ciências e correlatos. Tais buscas foram efetuadas com a finalidade de contemplar diferentes indicadores para o estudo da temática "ensino de Ciências por investigação nos anos iniciais do Ensino Fundamental". Seguindo esses indicadores, recuperamos 37 dissertações desenvolvidas entre os anos de 2010 a 2019. No quadro 2 apresentamos o quantitativo de estudos encontrados nas respectivas instituições de ensino e programas de pós-graduação.

Quadro 2 - Busca nas RIs -Abordagens investigativas no ensino de Ciências nos Anos Iniciais

\begin{tabular}{|c|c||c||c||}
\hline \hline & $\begin{array}{c}\text { Instituição de } \\
\text { ensino (RIs) }\end{array}$ & $\begin{array}{c}\text { Programas de } \\
\text { Pós-Graduação }\end{array}$ & $\begin{array}{c}\text { Ensino de Ciências, ensino por } \\
\text { investigação nos anos iniciais }\end{array}$ \\
\hline 1. & UFPA & PPGDOC & 01 dissertação \\
\hline 2. & IFES & PPGEDUCIMAT & 01 dissertação \\
\hline 3. & UFVJM & PPGECMaT & 12 dissertações \\
\hline 4. & IFG & PPGECM & 05 dissertações \\
\hline 5. & UTFPR & PPGFCET & 01 dissertação \\
\hline 6. & UFAL & PPGEN & 02 dissertações \\
\hline 7. & UFAC & MPECIM & 02 dissertações \\
\hline 8. & UNIVATES & PPGECE & 01 dissertação \\
\hline & & PPGEnFis & 02 dissertações \\
\hline 1. & UFES & PPGEEB & 01 dissertação \\
& & PPGE & 01 dissertação \\
\hline 10. & UFABC & MNPEF & 01 dissertação \\
\hline
\end{tabular}




\begin{tabular}{|c||c||c||c|}
\hline 11. & UFMG & PROMESTRE & 01 dissertação \\
\hline \hline 12. & UFN & PPGECIMAT & 01 dissertação \\
\hline 13. & USP & PPGEDUCIMAT & 01 dissertação \\
\hline 14. & UFRN & PPGECNM & 02 dissertações \\
\hline 15. & UNICSUL & PPGECM & 01 dissertação \\
\hline & TOTAL & 18 programas & 37 dissertações \\
\hline
\end{tabular}

Fonte: Costa; Guidotti (2020)

Os indicadores foram encontrados em dezoito programas de pós-graduação num total de quinze instituições de ensino, conforme a figura a seguir:

Figura 1 -RIs encontrados na busca

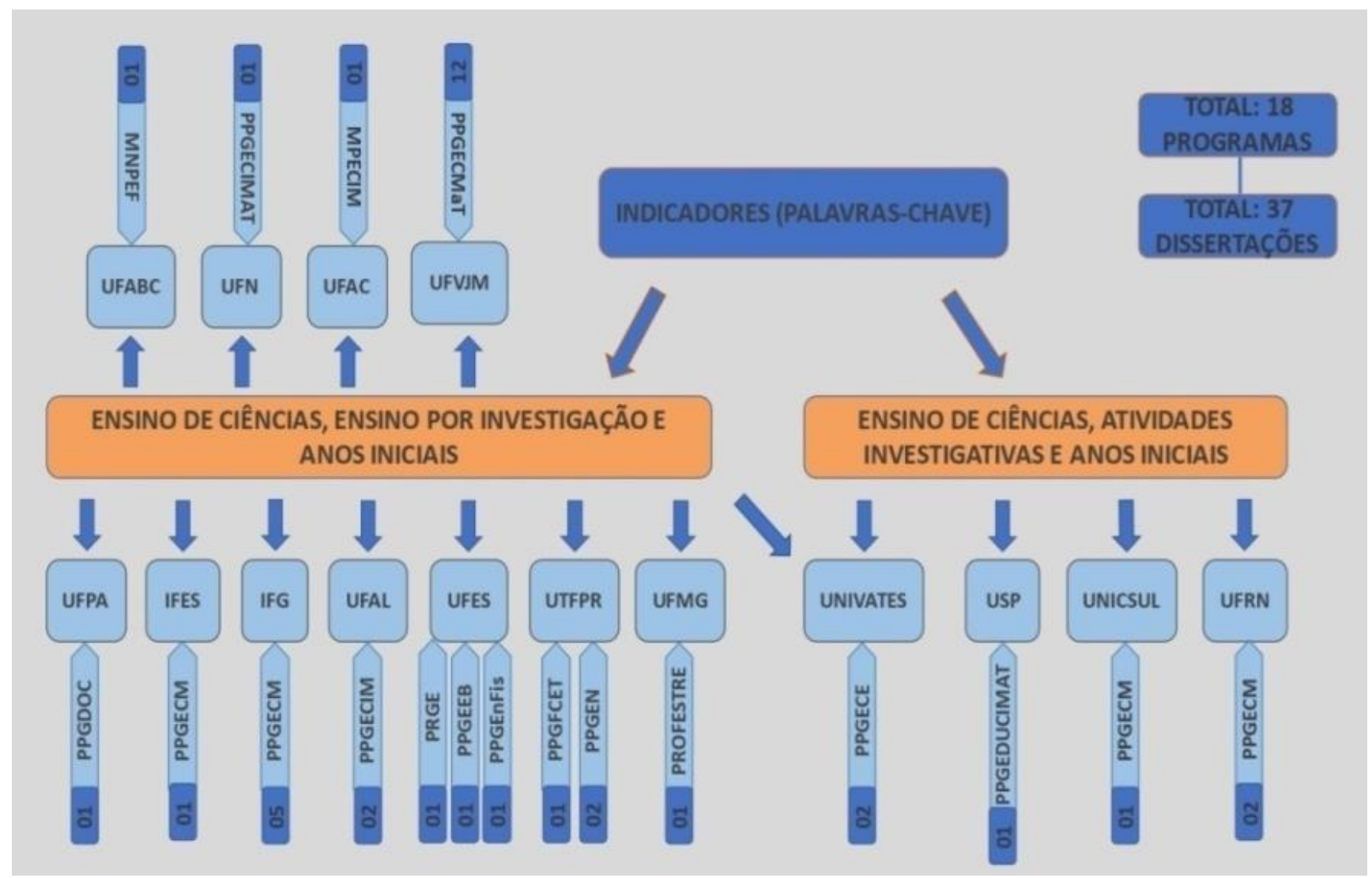

Fonte: Costa; Guidotti (2020)

Ao aprofundar a leitura dos resumos e procedimentos metodológicos das dissertações consideradas no quadro 2, os repositórios institucionais da UFAC (MPECIM), UFES (PPGE) e UFN (PPGECIMAT), foram descartados em razão de não atenderem o público-alvo de interesse desta pesquisa. Na UFRN (PPGECNM) e UFVJM (PPGECMaT) não constam incidências de estudos envolvendo a temática "ensino de Ciências por investigação nos anos iniciais do Ensino Fundamental". A UNICSUL (PPGECM), UFVJM (PPGECMaT) e UFABC (MNPEF) não foram analisadas, pois no período do estudo ${ }^{3}$, não disponibilizavam as dissertações produzidas.

A partir desses limitadores, consideramos neste estudo o quantitativo de dezoito dissertações, apresentadas no quadro 3:

\footnotetext{
${ }^{3} \mathrm{~A}$ busca pelas dissertações aconteceu entre os meses de janeiro e março do ano de 2020.
} 
Quadro 3 -Trabalhos selecionados

\begin{tabular}{|c|c|c|c|c|}
\hline Título & Autor & Ano & Programa & Instituição \\
\hline $\begin{array}{l}\text { A espiral investigativa como uma estratégia } \\
\text { de desenvolvimento da Alfabetização } \\
\text { Científica nos Anos Iniciais do Ensino } \\
\text { Fundamental }\end{array}$ & Mateus Lourenzon & 2018 & PPGECE & UNIVATES \\
\hline $\begin{array}{l}\text { Vai equilibrar? As contribuições da } \\
\text { sequência de ensino por investigação para } \\
\text { alfabetização em linguagem no ensino de } \\
\text { Ciências }\end{array}$ & $\begin{array}{l}\text { Thiago Wedson } \\
\text { Hilário }\end{array}$ & 2018 & PPGECM & IFG \\
\hline $\begin{array}{l}\text { Formação continuada de Professores dos } \\
\text { anos iniciais do Ensino Fundamental: Uma } \\
\text { proposta pautada em sequências de ensino } \\
\text { por investigação }\end{array}$ & $\begin{array}{l}\text { Helaíny Wanyessy } \\
\text { Kenya Rodrigues } \\
\text { Silva Chagas }\end{array}$ & 2018 & PPGECM & IFG \\
\hline $\begin{array}{l}\text { O ensino da interação radiação-corpo } \\
\text { humano nos anos iniciais do ensino } \\
\text { fundamental: uma abordagem investigativa } \\
\text { e colaborativa com enfoque ciência, } \\
\text { tecnologia e sociedade }\end{array}$ & $\begin{array}{l}\text { Leandro da Silva } \\
\text { Barcellos }\end{array}$ & 2017 & PPGENFIS & UFES \\
\hline $\begin{array}{l}\text { O desenvolvimento da argumentação em } \\
\text { atividades investigativas para alunos do } \\
\text { Ensino Fundamental }\end{array}$ & $\begin{array}{l}\text { Larissa Panlandi } \\
\quad \text { dos Reis }\end{array}$ & 2017 & PMPPEC & USP \\
\hline $\begin{array}{l}\text { Ensino de Ciências por investigação e } \\
\text { produção de textos: um diálogo possível } \\
\text { para a construção da autonomia de alunos } \\
\text { das séries iniciais }\end{array}$ & $\begin{array}{l}\text { Kátia Gonçalves } \\
\text { Zerlottini }\end{array}$ & 2017 & PPGED & UFMG \\
\hline $\begin{array}{l}\text { Ensino de Ciências por investigação para } \\
\text { professores da educação básica: } \\
\text { dificuldades e experiências de sucesso em } \\
\text { oficinas pedagógicas }\end{array}$ & $\begin{array}{l}\text { Maria Regina da } \\
\text { Costa Sperandio }\end{array}$ & 2017 & PPGEN & UTFPR \\
\hline $\begin{array}{l}\text { Aulas de Ciências: uso e desenvolvimento } \\
\text { de sequências investigativas }\end{array}$ & $\begin{array}{l}\text { Tamires Bartazar } \\
\text { Araújo }\end{array}$ & 2017 & PPGEN & UTFPR \\
\hline $\begin{array}{l}\text { Atividades experimentais: estratégia para } \\
\text { auxiliar no ensino de Ciências }\end{array}$ & $\begin{array}{l}\text { Jaciguara Queiroz } \\
\text { Pastana de Oliveira }\end{array}$ & 2017 & PPGECE & UNIVATES \\
\hline $\begin{array}{l}\text { Ensino de Ciências por investigação: um } \\
\text { desafio à formação dos professores dos } \\
\text { anos escolares iniciais }\end{array}$ & $\begin{array}{l}\text { Gilma Favacho } \\
\text { Amoras Soares }\end{array}$ & 2017 & PPGDOC & UFPA \\
\hline $\begin{array}{l}\text { O Ensino de Ciências Físicas por } \\
\text { Investigação: uma experiência nos anos } \\
\text { iniciais do Ensino Fundamental }\end{array}$ & $\begin{array}{l}\text { Gionani da Silva } \\
\text { Bayerl }\end{array}$ & 2016 & PPGEEB & UFES \\
\hline $\begin{array}{l}\text { Ensino de Ciências por investigação nos } \\
\text { anos iniciais do Ensino Fundamental: } \\
\text { estudo dos conceitos básicos de } \\
\text { eletricidade para a promoção da } \\
\text { alfabetização científica }\end{array}$ & $\begin{array}{l}\text { Lidiany Bezerra da } \\
\text { Silva de Azevero }\end{array}$ & 2016 & PPGECM & UFAL \\
\hline $\begin{array}{l}\text { Formação continuada de professores e a } \\
\text { metodologia de ensino por investigação nos } \\
\text { anos iniciais do Ensino Fundamental de } \\
\text { Paraúna-Go }\end{array}$ & $\begin{array}{l}\text { Marcelo Bueno } \\
\quad \text { Moura }\end{array}$ & 2016 & PPGECM & IFG \\
\hline
\end{tabular}




\begin{tabular}{|c|c|c|c|c|}
\hline $\begin{array}{l}\text { "Onde está o ar?" Sequência de ensino } \\
\text { investigativo para a promoção da } \\
\text { alfabetização científica de alunos do } 3^{\circ} \text { ano } \\
\text { do Ensino Fundamental }\end{array}$ & $\begin{array}{l}\text { Stephany Siqueira } \\
\text { Barbosa } \\
\text { Nascimento }\end{array}$ & 2016 & PPGECM & IFG \\
\hline $\begin{array}{l}\text { Práticas de ensino por investigação nas } \\
\text { aulas de Ciências desenvolvidas nos anos } \\
\text { iniciais do Ensino Fundamental }\end{array}$ & $\begin{array}{c}\text { José Augusto Real } \\
\text { Limeira }\end{array}$ & 2015 & PPGEFCET & UTFPR \\
\hline $\begin{array}{l}\text { A construção da argumentação no ensino } \\
\text { de Ciências por investigação visando à } \\
\text { promoção da alfabetização científica }\end{array}$ & $\begin{array}{c}\text { Ana Regina Mendes } \\
\text { e Silva Issa }\end{array}$ & 2015 & PPGECM & IFG \\
\hline $\begin{array}{l}\text { Ensino de Ciências por investigação: uma } \\
\text { estratégia pedagógica para promoção da } \\
\text { alfabetização científica nos primeiros anos } \\
\text { do Ensino Fundamental }\end{array}$ & $\begin{array}{l}\text { Liliane Oliveira de } \\
\text { Brito }\end{array}$ & 2014 & PPGECM & UFAL \\
\hline $\begin{array}{l}\text { Ensino por investigação nos anos iniciais: } \\
\text { análise de sequências didáticas de Ciências } \\
\text { sobre seres vivos na perspectiva da } \\
\text { alfabetização científica }\end{array}$ & $\begin{array}{c}\text { Patrícia Bastos } \\
\text { Leonor }\end{array}$ & 2013 & PPGECM & IFES \\
\hline
\end{tabular}

Fonte: Costa; Guidotti (2020)

Após esse primeiro fichamento dos trabalhos, buscamos extrair informações mais específicas e pertinentes aos objetivos do estudo, quais sejam: aportes teóricos, procedimentos metodológicos, problema ou questões de pesquisa e principais resultados. Este movimento analítico está descrito na próxima seção.

\section{O MOVIMENTO DE LER PARA COMPREENDER OS ESTUDOS}

$\mathrm{Na}$ seção anterior realizamos o mapeamento quantitativo de dissertações que se referiram, especificamente, aos indicadores da temática "abordagens investigativas no ensino de Ciências nos anos iniciais do Ensino Fundamental". No levantamento feito recuperamos dezoito dissertações.

Nesta seção apresentamos o segundo momento da análise que consiste em buscar, a contar da leitura dos resumos dos trabalhos, as seguintes informações: questão de pesquisa, procedimentos metodológicos, tipo de produto educacional e resultados. Nos resumos das produções podemos "lidar com os dados objetivos e concretos localizados nas indicações bibliográficas que remetem à pesquisa" (FERREIRA, 2002, p. 5) e igualmente catalogar essas produções, buscando tendências, relacionando ou distinguindo pesquisas entre si (Ibidem, 2002).

No entanto, na análise inicial das dissertações selecionadas, percebemos que alguns resumos não apresentavam todas as informações necessárias para o mapeamento. Diante da dificuldade que se apresentava foi preciso analisar as produções na íntegra, a fim de desenvolver o estudo abordado neste capítulo. A contar da leitura das dissertações, classificamos em duas categorias, de acordo com o público-alvo dos trabalhos.

\section{$\checkmark$ Categoria 1: Estudantes dos anos iniciais do Ensino Fundamental \\ $\checkmark$ Categoria 2: Professores dos anos iniciais do Ensino Fundamental}




\subsection{Estudos com foco nos estudantes dos anos iniciais do Ensino Fundamental}

As dissertações selecionadas nesta subseção abrangem estudos com os estudantes do $1^{0}$ ao $5^{\circ}$ ano do ensino fundamental. Nesta categoria foram recuperadas treze pesquisas (Quadro 4):

Quadro 4 - Categoria 1 - foco nos estudantes dos anos iniciais do Ensino Fundamental

\begin{tabular}{|c|c|c|c|}
\hline Autor (ANO) & Título da Dissertação & $\begin{array}{l}\text { Título do Produto } \\
\text { Educacional }\end{array}$ & Sigla do Programa \\
\hline $\begin{array}{l}\text { Lorenzon } \\
\text { (2018) }\end{array}$ & $\begin{array}{l}\text { A espiral investigativa como } \\
\text { uma estratégia de } \\
\text { desenvolvimento da } \\
\text { Alfabetização Científica nos } \\
\text { Anos Iniciais do Ensino } \\
\text { Fundamental }\end{array}$ & $\begin{array}{l}\text { Relatos de projetos de } \\
\text { investigação para o } \\
\text { desenvolvimento da } \\
\text { Alfabetização Científica em } \\
\text { crianças do } 3^{\circ} \text { ano do } \\
\text { Ensino Fundamental }\end{array}$ & PPGECE/UNIVATES \\
\hline Hilário (2018) & $\begin{array}{l}\text { Vai equilibrar? As contribuições } \\
\text { da sequência de ensino por } \\
\text { investigação para alfabetização } \\
\text { em linguagem no ensino de } \\
\text { Ciências } \\
\end{array}$ & $\begin{array}{l}\text { Sequência de ensino por } \\
\text { Investigação: Uma proposta } \\
\text { para o processo de } \\
\text { alfabetização }\end{array}$ & PPGECM/IFG \\
\hline Reis (2017) & $\begin{array}{c}\text { O desenvolvimento da } \\
\text { argumentação em atividades } \\
\text { investigativas para alunos do } \\
\text { Ensino Fundamental } \\
\end{array}$ & $\begin{array}{l}\text { Práticas experimentais } \\
\text { investigativas com enfoque } \\
\text { temático sobre "Dengue" }\end{array}$ & PMPPEC/USP \\
\hline Oliveira (2017) & $\begin{array}{l}\text { Atividades experimentais: } \\
\text { estratégia para auxiliar no } \\
\text { ensino de Ciências }\end{array}$ & $\begin{array}{l}\text { Atividades experimentais } \\
\text { sobre a temática água }\end{array}$ & PPGECE/UNIVATES \\
\hline Zerlottini (2017) & $\begin{array}{c}\text { Ensino de Ciências por } \\
\text { investigação e produção de } \\
\text { textos: um diálogo possível para } \\
\text { a construção da autonomia de } \\
\text { alunos das séries iniciais } \\
\end{array}$ & $\begin{array}{c}\text { Sequência didática sobre a } \\
\text { água }\end{array}$ & PPGED/UFMG \\
\hline Barcellos (2017) & $\begin{array}{l}\text { O ensino da interação radiação- } \\
\text { corpo humano nos anos iniciais } \\
\text { do ensino fundamental: uma } \\
\text { abordagem investigativa e } \\
\text { colaborativa com enfoque } \\
\text { ciência, tecnologia e sociedade } \\
\end{array}$ & $\begin{array}{l}\text { Sequência de Ensino } \\
\text { Investigativa Interação } \\
\text { Radiação-Corpo Humano }\end{array}$ & PPGENFIS/UFES \\
\hline Bayerl (2016) & $\begin{array}{l}\text { O Ensino de Ciências Físicas por } \\
\text { Investigação: uma experiência } \\
\text { nos anos iniciais do Ensino } \\
\text { Fundamental }\end{array}$ & $\begin{array}{c}\text { Atividades investigativas no } \\
\text { contexto da física clássica: } \\
\text { áreas da mecânica, } \\
\text { eletromagnetismo e } \\
\text { astronomia }\end{array}$ & PPGEEB/UFES \\
\hline Azevedo (2016) & $\begin{array}{c}\text { Ensino de Ciências por } \\
\text { investigação nos anos iniciais do } \\
\text { Ensino fundamental: estudo dos } \\
\text { conceitos básicos de eletricidade } \\
\text { para a promoção da } \\
\text { alfabetização científica } \\
\end{array}$ & $\begin{array}{c}\text { Ensino de Ciências nos Anos } \\
\text { Iniciais: Como trabalhar os } \\
\text { conteúdos de eletricidade } \\
\text { com a utilização de práticas } \\
\text { investigativas? }\end{array}$ & PPGECM/UFAL \\
\hline $\begin{array}{l}\text { Nascimento } \\
(2016)\end{array}$ & $\begin{array}{l}\text { "Onde está o ar?" Sequência de } \\
\text { ensino investigativo para a } \\
\text { promoção da alfabetização } \\
\text { científica de alunos do } 3^{\circ} \text { ano } \\
\text { do ensino fundamental }\end{array}$ & $\begin{array}{c}\text { Sequência de ensino } \\
\text { investigativo "Onde está o } \\
\text { ar?" }\end{array}$ & PPGECM/IFG \\
\hline
\end{tabular}




\begin{tabular}{|c|c|c|c|}
\hline Limeira (2015) & $\begin{array}{c}\text { Práticas de ensino por } \\
\text { investigação nas aulas de } \\
\text { Ciências desenvolvidas nos anos } \\
\text { iniciais do ensino fundamental }\end{array}$ & $\begin{array}{c}\text { Propostas de Práticas de } \\
\text { Ensino por Investigação nas } \\
\text { Aulas de Ciências dos Anos } \\
\text { Iniciais do Ensino } \\
\text { Fundamental } \\
\end{array}$ & PPGEFCET/UTFPR \\
\hline Issa (2015) & $\begin{array}{l}\text { A construção da argumentação } \\
\text { no ensino de Ciências por } \\
\text { investigação visando à } \\
\text { promoção da alfabetização } \\
\text { científica }\end{array}$ & $\begin{array}{c}\text { Sequência de ensino } \\
\text { investigativo "Colocando as } \\
\text { bolinhas na cestinha" }\end{array}$ & PPGECM/IFG \\
\hline Brito (2014) & $\begin{array}{c}\text { Ensino de Ciências por } \\
\text { investigação: uma estratégia } \\
\text { pedagógica para promoção da } \\
\text { alfabetização científica nos } \\
\text { primeiros anos do ensino } \\
\text { fundamental } \\
\end{array}$ & $\begin{array}{c}\text { Sequência didática "De onde } \\
\text { vem?" }\end{array}$ & PPGECM/UFAL \\
\hline Leonor (2013) & $\begin{array}{c}\text { Ensino por investigação nos } \\
\text { anos iniciais: análise de } \\
\text { sequências didáticas de Ciências } \\
\text { sobre seres vivos na perspectiva } \\
\text { da alfabetização científica }\end{array}$ & $\begin{array}{l}\text { Sequências didáticas de } \\
\text { Ciências: } \\
\text { Ensino por investigação nos } \\
\text { Anos Iniciais do Ensino } \\
\text { Fundamental }\end{array}$ & PPGECM/IFES \\
\hline
\end{tabular}

Fonte: Costa; Guidotti (2020)

À continuidade deste trabalho, discorremos sobre cada uma destas dissertações apresentadas no quadro acima (4), destacando aspectos que contribuem ao objetivo deste artigo.

Na pesquisa de Lorenzon (2018) destacamos que o autor almejou apurar as discussões existentes entre o ensino por investigação e alfabetização científica. A questão da pesquisa objetivou analisar de que modo a participação em projetos de investigação fomenta o desenvolvimento da alfabetização científica em crianças do terceiro ano do Ensino Fundamental de uma escola pública localizada em Arroio do Meio/RS. $O$ trabalho apresentou uma abordagem qualitativa do tipo pesquisa-ação e o corpus da pesquisa foi analisado mediante a aplicação do método de análise textual discursiva (ATD).

Lorenzon (2018) fez um apanhado histórico sobre a trajetória do ensino de Ciências e os termos da alfabetização científica e ainda sobre o ensino por investigação e o educar pela pesquisa. $O$ autor assumiu que a proposta de ensino por investigação e o educar pela pesquisa compartilham alguns pressupostos de caráter construtivista, mesmo que resguardem diferenças significativas. Na proposta de investigação no contexto escolar, estabeleceu bases em Silva (2011) e Ramos (2012), e ressaltou a importância da comunicação e a elaboração da argumentação.

A proposição do produto educacional foi relatos escritos dos projetos investigativos realizados em sala de aula com os estudantes. As temáticas daqueles discorreram acerca das curiosidades epistêmicas emergentes do cotidiano da turma. Os principais instrumentos utilizados foram audiovisuais, portfólios, desenhos, textos jornalísticos, infográficos, maquetes e os experimentos realizados pelos estudantes.

Os resultados do estudo foram consideráveis, segundo o autor. Lorenzon (2018) salientou que no início do projeto o professor necessitou agir de forma mais atuante, visto que os estudantes não estavam familiarizados com a proposta. No entanto, com o passar do tempo, conseguiram desenvolver argumentações e levantar hipóteses. Lorenzon (2018) analisou a questão de pesquisa com embasamentos nos eixos estruturantes da alfabetização científica proposto por Carvalho e Sasseron (2011). Concluiu que projetos investigativos podem desenvolver a alfabetização científica, 
como também é, "por meio da investigação de fenômenos cotidianos e a busca por explicá-los de modo mais rigoroso, que a criança conseguirá desenvolver sua criticidade e realizar novas leituras do mundo que está inserido" (LORENZON, 2018, p. 215).

Oliveira (2017) iniciou seu estudo com o objetivo de investigar como as atividades experimentais podem auxiliar no ensino de Ciências com os alunos do quinto ano do Ensino Fundamental em uma escola pública no Estado do Amapá. A autora almejou práticas diferentes do contexto atual, onde desenvolveu a pesquisa e a (re) estruturação das metodologias do ensino de Ciências, visando uma melhoria na educação.

Desenvolveu uma pesquisa qualitativa da modalidade estudo de caso e, bibliográfica do tipo "estado da arte" sobre a temática. Teve como finalidade encontrar evidências de que as atividades experimentais investigativas são importantes no processo de ensino de Ciências. A pesquisadora analisou seis dissertações de mestrado, publicadas nos anos 2011 a 2013, em distintos programas de modalidades acadêmicas e profissionais.

Assim como Lorenzon (2018), a autora Oliveira (2017) sintetizou a trajetória do ensino de Ciências focalizando nas melhorias do ensino com abordagens investigativas experimentais. Ressaltou que os experimentos estabelecem uma relação entre a teoria e prática, tornando-os essenciais e agentes motivadores para a sala de aula. Reconhece que o ensino de Ciências para ser significativo, é fundamental que parta do conhecimento prévio dos sujeitos, que relação do professor com o estudante é importante e a escola constitui-se em um espaço de relação potencialmente dialógica.

Como produto educacional, Oliveira (2017) desenvolveu atividades investigativas experimentais para o ensino dos conteúdos sobre o ciclo da água; estados físicos da água; água como solvente e, tratamento da água para o consumo humano. As atividades experimentais foram elaboradas com materiais sustentáveis e de simples acesso. Como instrumentos para o levantamento de dados, a pesquisadora utilizou diário de bordo, gravações de áudios, questionários e vídeo.

Ao concluir a pesquisa, Oliveira (2017) ressaltou que as atividades experimentais no ensino de Ciências provocaram o interesse, a curiosidade, o desejo pela descoberta e a interação entre os estudantes. A autora afirmou que as atividades investigativas experimentais possibilitaram 0 desenvolvimento da criticidade, do experimentar, do levantar hipóteses, do observar e da argumentação, assim como Lorenzon (2018) também ressaltou em suas considerações finais.

Em seus estudos, Bayerl (2016) também desenvolveu atividades experimentais com estudantes do quarto e quinto ano. Em seu trabalho analisou sobre a introdução dos alunos ao universo da ciência, a contextualização histórica do ensino de Ciências, o ensino por investigação e alfabetização científica. O autor objetivou mostrar que, com a metodologia de ensino por investigação, os estudantes conseguem compreender conceitos de Ciências Físicas na primeira etapa do Ensino Fundamental. Realizou o estudo utilizando a metodologia de pesquisa qualitativa de modalidade exploratória. Para trilhar os caminhos de seus estudos, filmou os encontros com os estudantes a fim de selecionar a sequência das atividades aplicadas que foram intituladas como Episódios de Ensino, tendo como base os conceitos de Carvalho (1992). Bayerl (2016) analisou os relatórios das atividades investigativas e o portfólio do pesquisador.

O produto educacional foi elaborado com quatro atividades investigativas no contexto da física clássica (áreas da mecânica, eletromagnetismo e astronomia) no período de cinco semanas, perfazendo um total de 20h/aula. Bayerl (2016) ressaltou que os estudantes, ao realizarem as atividades 
experimentais, envolveram-se cognitiva e afetivamente. Os autores Oliveira (2017) e Bayerl (2016) afirmaram que, ao proporem as atividades investigativas, os estudantes tiveram a oportunidade de contrapor as ideias prévias, as hipóteses e a comunicação dos resultados.

Bayerl (2016, p. 112) constatou nas considerações finais de seu estudo que "os estudantes quando envolvidos e estimulados podem depreender conceitos das Ciências Físicas. Estes conceitos poderão ser ampliados ou reproduzidos ao relacionarem com fenômenos físicos do cotidiano".

A autora Issa (2015) desenvolveu sua pesquisa sobre a construção da argumentação no ensino de Ciências por investigação, também, com a elaboração de atividades experimentais. Realizou os estudos com estudantes do quarto ano do Ensino Fundamental de uma escola particular da cidade de Jataí/GO. Issa (2015) identificou e discutiu como os alunos dos Anos Iniciais constroem seus argumentos e quais indicadores da alfabetização científica estão presentes na resolução de um problema de caráter investigativo. O trabalho foi desenvolvido em uma abordagem qualitativa, predominantemente descritiva, embasada por autores que articulam e caracterizam proposições sobre o ensino de Ciências, alfabetização científica e ensino por investigação.

O produto educacional foi constituído por um aparato composto de um trilho e duas bolinhas, intitulado "Colocando as bolinhas na cestinha". O experimento partiu de uma proposta metodológica realizada pelo LaPEF (Laboratório de Pesquisa em Ensino de Física), sob a coordenação da professora Anna Maria Pessoa de Carvalho. Issa (2015) selecionou uma das atividades do LaPEF, cujo título é "O problema da cestinha" que serviu de inspiração para sua proposta

De acordo com Issa (2015, p. 6) nos resultados da pesquisa, "foi possível observar a presença de vários indicadores da Alfabetização Científica. Percebeu-se com frequência o uso do indicador de organização de informações, explicação e justificativa e levantamento de hipóteses". A autora ressaltou que a proposta do experimento, com abordagem de ensino por investigação, proporcionou aos estudantes o desenvolvimento da tomada de decisão, o levantar hipóteses para a solução de problemas, a criatividade e construção de argumentações.

A pesquisa de Limeira (2015) analisou as práticas de ensino de Ciências realizadas na primeira etapa escolar, a fim de diagnosticar limites e dificuldades para a execução de atividades experimentais investigativas em sala de aula. O autor desenvolveu as atividades com estudantes da rede pública do quinto ano do Ensino Fundamental da cidade de Curitiba.

Limeira (2015) fundamentou sua obra no ensino de Ciências por investigação e o construtivismo pela perspectiva de Moraes e Ramos (1998) e Weissmann (1988). Na metodologia de pesquisa seguiu os caminhos da pesquisa qualitativa, sem definir a modalidade.

O produto educacional foi elaborado com cinco atividades experimentais investigativas como propostas de práticas de ensino por investigação nas aulas de Ciências, abordando diferentes conteúdos de aspectos conceituais do $5^{\circ}$ ano do Ensino Fundamental. Conforme Limeira (2015) 0 material foi desenvolvido com a finalidade de possibilitar aos professores das escolas do município subsídios teóricos que constituem essa concepção de ensino, além de disponibilizar sugestões de atividades.

Ao finalizar a pesquisa, Limeira (2015) concluiu que, durante a realização das atividades, houve dificuldades de espaço e de materiais para o desenvolvimento da proposta que solicitou ações investigativas dos estudantes. Assim, foi necessário adquirir materiais próprios para a aplicação das 
práticas. Através desse movimento, alcançou o objetivo desta pesquisa, salientando que o ensino por investigação é uma abordagem em que "professores e estudantes tornam-se parceiros e coautores na construção do conhecimento, motivando-se e entusiasmando-se diante das descobertas e compreensão do mundo ao qual pertencem" (LIMEIRA, 2015, p. 101).

Na pesquisa de Hilário (2018) o ensino de Ciências por investigação foi elaborado em sequência de ensino por investigação (SEI) pela perspectiva de Carvalho 2011 e Carvalho e Sasseron (2008). 0 autor objetivou responder como o uso de uma SEI sobre conhecimento físico pode contribuir para o processo de alfabetização cientifica (AC) de uma turma do segundo ano do Ensino Fundamental, situada na periferia da região metropolitana de Goiânia/GO. A metodologia de pesquisa foi de uma abordagem qualitativa do tipo estudo de caso.

O produto educacional foi organizado por uma SEI, estruturada pela proposta de Carvalho (2009). Era composta por três kits de experimentação para trabalhar o equilíbrio físico em sala de aula e um caderno de orientações teóricas e metodológicas. Para Hilário (2018) o desenvolvimento da SEI proporcionou aos estudantes não apenas a participação ativa em sala de aula, mas também o envolvimento deles diante dos desafios propostos e o compartilhamento de experiências e saberes entre os pares. O autor ressaltou que a SEI colaborou para o desenvolvimento dos processos de aprendizagem, no que diz respeito à leitura, produção escrita e oralidade. Ressaltou também que "as atividades encorajaram a curiosidade dos alunos, provocou a busca por explicações e descobertas, relacionando o conhecimento científico com o seu dia a dia" (HILÁRIO, 2018, p. 123).

O autor destacou que não foi fácil o uso de experimentos com enfoque investigativo. Os estudantes apresentaram dificuldades para sistematizar as ações na busca da solução de problemas, pois necessitavam "de mais tempo para gerar conhecimento" (p.124).

A pesquisadora Azevedo (2016) realizou o trabalho para compreender os processos da alfabetização científica (AC) através do ensino de Ciências por investigação. Ela analisou se essa abordagem poderia contribuir para a AC ao realizar uma SEI com os estudantes do quinto ano do Ensino Fundamental. O procedimento metodológico utilizado pela autora foi pesquisa de campo de cunho qualitativo, do tipo pesquisa-ação.

O produto educacional de Azevedo (2016) foi uma SEI sobre os conceitos básicos de eletricidade e a prática de circuitos elétricos. Baseou-se pela proposta de Carvalho (2013) para o possível desenvolvimento das capacidades cognitivas. A pesquisadora elaborou uma cartilha de apoio aos professores composta por textos teóricos, experimentos, gibis e vídeos.

Segundo Azevedo (2016), a elaboração da SEI foi satisfatória, considerando que os estudantes desenvolveram o senso argumentativo, o aprimoramento da escrita e interagiram nos grupos, assim como também fora constatado nos estudos de Hilário (2018). O ensino por investigação promoveu entre os alunos "vários momentos de aprendizagem, aproximando ainda mais do saber científico e desencadeando indicadores e habilidades que podem tornar o aluno alfabetizado cientificamente" (AZEVEDO, 2016, p. 109).

Nascimento (2016) desenvolveu estudos sobre o ensino por investigação com enfoque na promoção da alfabetização científica (AC) dos estudantes do terceiro ano do Ensino Fundamental. Buscou identificar as contribuições de uma SEI utilizando uma experimentação para promover a AC. Como metodologia de pesquisa, Nascimento (2016) usou uma abordagem qualitativa, da modalidade estudo de caso e bibliográfica, sobre o ensino de Ciências nos Anos Iniciais do Ensino Fundamental. O autor 
tinha como finalidade entender os aspectos pedagógicos e referenciais teóricos para a sua pesquisa e para tanto, fundamentou seus estudos nas autoras Sasseron e Carvalho $(2008 ; 2011 ; 2013)$.

A autora Nascimento (2016) realizou a SEI com uma atividade experimental sobre o ar, como produto educacional. A proposta foi organizada pelas etapas de Carvalho (1998) e procurou favorecer o desenvolvimento de habilidades e competências que aproximassem os estudantes da $A C$, do experimento científico e do ensino investigativo.

Ao concluir o trabalho, Nascimento (2016) afirmou que a SEI favoreceu a aprendizagem dos estudantes no processo de construção da AC. A maioria da turma do terceiro ano agregou a relação com o experimento ao seu cotidiano, expressando seus conhecimentos de forma oral, gestual e escrita. A SEI promoveu a interação dos estudantes e professor, a criticidade e a autonomia, tal como nos estudos de Hilário (2018).

A pesquisa de Brito (2014) baseou-se no ensino de Ciências por investigação como uma prática que facilita a AC. A questão-problema era saber se, nos primeiros anos do Ensino Fundamental, o ensino de Ciências por investigação é uma estratégia metodológica eficiente para a promoção da $A C$. $A$ metodologia de pesquisa foi qualitativa, do tipo pesquisa-ação.

O produto educacional elaborado pela autora foi uma SEI denominada "De onde vem?", com estudantes do quinto ano do Ensino Fundamental e tinha como foco o ensino do conhecimento físico. O objetivo da SEI foi promover a AC no sentido de compreender conceitos científicos e termos básicos fundamentais, baseada em Sasseron (2007). A produção final dos alunos foi um CD de dados contendo materiais teóricos e práticos de auxílio aos professores para o planejamento de atividades que possibilitem a AC.

A autora Brito (2014) finalizou seus estudos revelando que os estudantes eram capazes de utilizar conceitos científicos através da leitura, compreensão e "significação do mundo" (p. 8). As atividades possibilitaram aos alunos elaborar hipóteses, aprender coletivamente e contextualizar 0 conhecimento. Para Brito (2014), tal como Nascimento (2016) e Hilário (2018), o ensino por investigação é uma abordagem de ensino que desenvolve a autonomia e criticidade, abordagem essa em que "os discentes não pensam no mundo de forma ingênua, isto é, de forma acrítica com evidências superficiais" (BRITO, 2014. p. 122).

O estudo de Leonor (2013) foi desenvolvido através de uma análise de sequência didática de Ciências, pela abordagem de ensino por investigação, com estudantes do primeiro ano do Ensino Fundamental do município de Vitória-ES. A questão-problema dessa pesquisa foi analisar a maneira como o ensino por investigação favorece a AC nos estudantes. O estudo apresenta um breve resgate histórico do ensino de Ciências no Brasil e do ensino por investigação e a metodologia de pesquisa foi qualitativa teórico-empírica, do tipo estudo de caso.

O produto educacional constituiu-se num guia didático de Ciências, elaborada com duas SEIs: "Pequenino seres vivos" e "Vim ver a vida" e ainda um livro paradidático intitulado "Curuquerê, as aventuras da lagarta da couve". As atividades tiveram como objetivo contribuir para a construção de saberes científicos, incentivando a leitura e a escrita.

$\mathrm{Na}$ análise dos resultados, de acordo com Leonor (2013), entende-se que foi possível a aprendizagem dos conteúdos científicos no primeiro ano do Ensino Fundamental, estimulando a $A C$ através da abordagem do ensino por investigação. Essa perspectiva de ensino "contribuiu para 0 
desenvolvimento de posturas e ideais sustentáveis por parte desses sujeitos, além do exercício da criticidade e do questionamento" (LEONOR, 2013, p. 159).

A autora Reis (2017) também desenvolveu seu estudo com SEI inspirada na proposta apresentada por Carvalho et al (2013). Suas escritas movimentaram-se ao viés da argumentação no ensino e o histórico das Ciências no Ensino Fundamental. . O objetivo foi "investigar o desenvolvimento da argumentação científica por meio de atividades investigativas com os estudantes do quinto ano do Ensino Fundamental, explorando conteúdos físicos" (REIS, 2017, p. 7) com a temática "A dengue". 0 estudo não deixou claro que tipo de abordagem metodológica foi utilizado na pesquisa; no entanto, informa que os principais dados coletados foram a palavra, a linguagem utilizada e os termos adquiridos pelos estudantes para expressarem suas ideias e hipóteses.

O produto educacional de Reis (2017) foi constituído por uma SEI intitulada como: "Práticas experimentais investigativas com enfoque temático sobre a dengue, $[\ldots]$ a fim de promover 0 desenvolvimento argumentativo científico nos alunos, como também, contextualizar os conteúdos propostos com a realidade local"' (REIS, 2017, p. 59).

Ao concluir a pesquisa, Reis (2017) compreendeu que as atividades investigativas nos anos iniciais possibilitam aos estudantes a argumentação científica. Assim como a autora Leonor (2013), Reis (2017) também evidenciou que através do ensino por investigação, os estudantes utilizam suas experiências anteriores para compreender os conteúdos, comunicando os saberes com os pares. A autora considerou que o ensino por investigação oportunizou aos estudantes aprenderem "aspectos próprios da linguagem e do fazer científico: levantando hipóteses, realizando testes experimentais, discutindo modelos explicativos, escrevendo relatórios científicos"' (REIS, 2017, p. 123).

No estudo de Zerlottini (2017) o ensino de Ciências por investigação foi aplicado com os princípios da SEI. A autora desenvolveu a pesquisa para apurar se nas aulas de Ciências com caráter investigativo se desenvolve a autonomia entre os estudantes quando utilizam produções textuais. A fundamentação teórica buscou reflexões sobre o ensino de Ciências na perspectiva investigativa com a teoria da autodeterminação de Derci e Ryan (1985) e Ryan e Derci (2000). A pesquisa foi elaborada pela metodologia de pesquisa-ação participativa.

O produto educacional foi organizado por uma sequência didática, embasada em dois campos conceituais: Ensino de Ciências por investigação e motivação extrínseca com ênfase na autonomia. A SEI foi elaborada com os estudantes do quarto ano do Ensino Fundamental e teve como tema o ciclo da água na natureza. Nessa atividade foi construído um terrário como ferramenta pedagógica e dois cadernos com orientações: um para os alunos e outro para os professores. O produto teve a proposta de produzir quatro poemas e os estudantes criaram, coletivamente, na turma em pequenos grupos ou individualmente.

A autora Zerlottini (2017, p. 112) concluiu que o ensino por investigação "foi peça propulsora na construção da autonomia dos alunos". Os estudantes desenvolveram a escrita e aprenderam de forma criativa e com autoria. Assim como os demais autores citados anteriormente, Zerlottini (2017) salientou que a interação entre os pares aprimorou a comunicação e a tomada de decisão em sala de aula.

A obra de Barcellos (2017) também desenvolveu uma abordagem investigativa no ensino de Ciências, no entanto com enfoque na Ciência, Tecnologia e Sociedade (CTS). O tema possui caráter interdisciplinar e sociocientífico e teve como objetivo "analisar como uma intervenção educacional 
com enfoque CTS e pautada no ensino por investigação contribui para o entendimento dos estudantes do quinto ano do Ensino Fundamental" (BARCELLOS, 2017, p. 42). Como delineamento metodológico, a pesquisa foi uma abordagem colaborativa.

O produto educacional de Barcellos (2017) constituiu-se por uma SEI baseado em Carvalho (2013), com as temáticas: interação, radiação ultravioleta e corpo humano. Os objetivos de aprendizagem da SEI foram estruturados nas dimensões conceitual, procedimental e atitudinal (POZO E GOMEZCRESPO 2009).

Nas considerações finais, Barcellos (2017, p. 114) apontou que o ensino por investigação pode "potencializar a construção de conceitos e o desenvolvimento de atitudes e procedimentos, e que os estudantes foram capazes de construir modelos estruturados". Conforme o autor, ao longo do projeto os estudantes adquiriram habilidades em realizar perguntas, criar hipóteses, estabelecer diálogos e promover a conscientização.

\subsection{Estudos com foco nos professores dos anos iniciais do Ensino Fundamental}

Nesta subseção enquadramos dissertações que englobam estudos realizados com professores dos anos iniciais do Ensino Fundamental. Para esta categoria foram resgatados cinco trabalhos que, à continuidade apresentaremos as sinopses de cada uma delas, enfatizando algumas particularidades que contribuem com o nosso propósito de estudo.

Quadro 5 - Categoria 2 -Estudos com foco nos professores dos anos iniciais do Ensino Fundamental

\begin{tabular}{||l||c||c|c||}
\hline Autor (ANO) & Título da Dissertação & $\begin{array}{c}\text { Título do Produto } \\
\text { Educacional }\end{array}$ & $\begin{array}{c}\text { Sigla do } \\
\text { Programa }\end{array}$ \\
\hline \hline Chagas (2018) & $\begin{array}{c}\text { Formação continuada de } \\
\text { Professores dos Anos Iniciais do } \\
\text { Ensino Fundamental: Uma } \\
\text { proposta pautada em sequências } \\
\text { de ensino por investigação }\end{array}$ & $\begin{array}{c}\text { Curso de extensão "A utilização } \\
\text { de sequência de ensino } \\
\text { investigativa no ensino de } \\
\text { ciências para os Anos Iniciais } \\
\text { do Ensino Fundamental" }\end{array}$ & PPGECM/IFG \\
\hline \hline $\begin{array}{l}\text { Sperandio } \\
\text { (2017) }\end{array}$ & $\begin{array}{c}\text { Ensino de Ciências por } \\
\text { investigação para professores da } \\
\text { educação básica: dificuldades e } \\
\text { experiências de sucesso em } \\
\text { oficinas pedagógicas }\end{array}$ & $\begin{array}{c}\text { Material didático-pedagógico na } \\
\text { perspectiva do ensino de } \\
\text { Ciências por investigação para } \\
\text { professores dos Anos Iniciais do } \\
\text { Ensino Fundamental }\end{array}$ & PPGEN/UTFPR \\
\hline \hline $\begin{array}{c}\text { Araújo (2017) } \\
\text { desenvolvimento de sequências } \\
\text { investigativas }\end{array}$ & $\begin{array}{c}\text { Proposta para o } \\
\text { desenvolvimento de sequência } \\
\text { investigativa em Ciências }\end{array}$ & PPGEN/UTFPR \\
\hline \hline Soares (2017) & $\begin{array}{c}\text { Ensino de Ciências por } \\
\text { investigação: um desafio à } \\
\text { formação dos professores dos } \\
\text { anos escolares iniciais }\end{array}$ & Fórum de formação & PPGDOC/UFPA \\
\hline \hline Moura (2016) & $\begin{array}{c}\text { Formação continuada de } \\
\text { professores e a metodologia de } \\
\text { ensino por investigação nos anos } \\
\text { iniciais do ensino fundamental de } \\
\text { Paraúna/GO }\end{array}$ & $\begin{array}{c}\text { Curso de Formação Continuada } \\
\text { para Professores em Paraúna }\end{array}$ & PPGECM/IFG \\
\hline
\end{tabular}

Fonte: Costa; Guidotti (2020)

A pesquisa de Soares (2017) procurou compreender as contribuições que o ensino por investigação pode promover na formação de professores que lecionam Ciências para os anos iniciais do Ensino 
Fundamental. Salientou no trabalho os caminhos históricos do ensino de Ciências, das atividades investigativas e a formação de professores como prática reflexiva e contínua. A metodologia de pesquisa foi qualitativa, nas modalidades narrativa e pesquisa-formação, e para o tratamento de dados a ATD.

O produto educacional de Soares (2017) foi constituído por encontros formativos com três professores do terceiro ao quinto ano do Ensino Fundamental, intitulado como "Fóruns de formação". Foram realizados sete fóruns, num total de vinte e oito encontros, nos quais foram abordadas questões referentes ao PCN de Ciências, conteúdos programáticos, planejamento, ensino por investigação e experimentos. Os professores participantes realizaram experimentos para cada ano do Ensino Fundamental, porém não os aplicaram com os estudantes.

Nas considerações finais, Soares (2017) concluiu que os professores participantes refletiram sobre sua prática em sala de aula, dando novos significados e propondo atividades investigativas. A autora salientou que, com o ensino por investigação, o professor "contribui para promover junto aos estudantes o hábito da pesquisa como uma possibilidade de aprimorar o processo de ensinar e aprender, contribuindo para a formação de sujeitos capazes de compreender, questionar e se posicionar" (SOARES, 2017, p 73).

Moura (2016) também almejou compreender as contribuições do ensino por investigação na formação continuada de professores na sua pesquisa. Ela foi direcionada às atividades experimentais investigativas e contou com a participação de dez professores do terceiro ao quinto ano do Ensino Fundamental da rede pública. Analisou subjetivamente sobre o contexto histórico do ensino de Ciências, a formação de professores, o ensino por investigação e Ciências físicas. Como procedimento metodológico utilizou a pesquisa-ação de cunho qualitativo.

O pesquisador Moura (2016) realizou um curso de formação continuada para professores como produto educacional. A formação de $80 \mathrm{~h} /$ aula foi desenvolvida nas modalidades presenciais e virtualmente através do ambiente virtual moodle. O que difere da pesquisa de Soares (2017) é que Moura (2016) propôs aos professores a aplicação de experimentos aos seus alunos.

Ao concluir, Moura (2016) considerou que os professores no início do curso apresentaram muitas dificuldades em entender a metodologia e os conhecimentos físicos relacionados. Segundo Moura (2016), a aplicação dos experimentos com os estudantes foi necessária para a compreensão e mudança de perspectivas. Definiu que o ensino de Ciências demanda proporcionar aos alunos uma educação de qualidade que "vise à prática de investigação, que está muito além de aprender Ciências de forma teórica, mas uma prática voltada para a reflexão, que parte de uma situação problema e que leva o aluno ao conhecimento científico" (MOURA, 2016, p. 82).

Chagas (2018) pesquisou sobre o ensino de Ciências por investigação e objetivou analisar as colaborações da SEI na aprendizagem dos estudantes. Destacou sobre a visão construtivista dessa abordagem, como também, dos marcos legais no ensino de Ciências e as tendências metodológicas investigativas. O trabalho foi caracterizado pela pesquisa qualitativa, na modalidade estudo de caso.

O produto educacional da autora Chagas (2018) foi fomentado por um curso de extensão de 80h/aula com o propósito de aprimorar as práticas pedagógicas. Desenvolveu SEIs com seis professoras, inspirado pelas atividades do LaPEF, que são embasadas por Carvalho et al (2009). Com temáticas estabelecidas como etapas da formação, os participantes do curso aplicaram a SEI em suas turmas. 
A autora finalizou no trabalho que os pesquisados repetiram padrões de seus professores do ensino básico e que valorizaram mais a alfabetização do que as aulas de Ciências. Destacou que a SEI, na perspectiva do ensino por investigação, proporcionou ao grupo de professoras a aprendizagem de uma abordagem inovadora que ocasionou autonomia e aprimoramento da escrita, tendo em vista que "a disciplina de Ciências pode ser introduzida no planejamento de forma interdisciplinar com a língua portuguesa" (CHAGAS, 2018, p.124).

A obra de Araújo (2017) também se refere ao estudo sobre SEI no ensino de Ciências por investigação. A autora buscou entender as concepções e as reflexões de duas professoras sobre como uma SEI pode contribuir para a própria formação. Retratou a respeito da formação continuada, da ação docente em sala de aula e a abordagem de ensino investigativa. A metodologia de pesquisa foi qualitativa, na modalidade estudo de caso.

A proposta de Araújo (2017) para o produto educacional foi um curso de formação para o projeto de iniciação científica. O curso, com duração de seis meses, foi intitulado como "Proposta para o desenvolvimento de sequência investigativa em Ciências". Nessa formação foram abordados aspectos relacionados às etapas da SEI. Correspondente aos estudos de Chagas (2018), na pesquisa de Araújo (2016) os professores participantes também aplicaram a SEI em suas salas de aula, no entanto, levou-se apenas a temática e os estudantes elaboraram as questões problemas.

Araújo (2016) finalizou seu trabalho salientando que os professores aprimoraram sua formação docente, bem como constataram a necessidade de qualificações contínuas. Perceberam que o ensino por investigação "promove situações de aprendizagem a partir de situações cotidianas e de curiosidades das próprias crianças advindas do contato com o mundo que a cerca" (ARAÚJO, 2016, p. 134).

A autora Sperandio (2017), da mesma forma que os autores anteriores, investigou o quanto um curso de formação de professores pode contribuir para a prática pedagógica na perspectiva do ensino por investigação. A metodologia utilizada foi a qualitativa analítica e descritiva.

O produto educacional também foi uma formação continuada para docentes da oficina pedagógica de uma escola municipal, baseada por SEI sobre vegetais e o ambiente. No decorrer do curso foram desenvolvidos estudos e pesquisas, aulas expositivas e dialogadas, vivências de experimentos investigativos e trocas de experiências. A SEI foi elaborada durante o curso e não foi aplicada com os estudantes. $O$ produto educacional resultou em um material didático-pedagógico, com a abordagem de ensino por investigação e sequência didática.

Nas conclusões deste estudo, Sperandio (2017) salientou que a formação contribuiu para o planejamento e a reflexão dos professores na realização de atividades investigativas centradas no aluno, valorizando assim o aprendizado. A autora complementou ainda que, nas atividades pedagógicas investigativas, o diferencial para o sucesso "é o professor ter em mente a importância da elaboração do problema para motivar a participação dos alunos, o qual pode partir dele ou dos próprios alunos" (SPERANDIO, 2017, p. 94).

\section{CONSIDERAÇÕES FINAIS}

A contar do movimento apresentado nas seções anteriores, destacamos no quadro 6, aspectos teórico-práticos emergentes da análise das dissertações encontradas: 
Quadro 6 - Aspectos emergentes da análise

\section{ASPECTOS EMERGENTES DA ANÁLISE SOBRE PROJETOS INVESTIGATIVOS NOS ANOS INICIAIS DO ENSINO FUNDAMENTAL}

$\checkmark$ Proporciona a interdisciplinaridade;

$\checkmark$ Contribui para o desenvolvimento de posturas e ideias sustentáveis;

$\checkmark$ Possibilita a AC;

$\checkmark$ Necessita partir do conhecimento prévio dos sujeitos;

$\checkmark$ Relação do professor e estudante é muito importante;

$\checkmark$ Professores e alunos parceiros e coautores na construção do conhecimento;

$\checkmark$ Propicia a comunicação, a argumentação e a criticidade;

$\checkmark$ Representa um espaço de relações dialógicas;

$\checkmark$ Oportunidade de contrapor as ideias e a comunicação dos resultados;

$\checkmark$ Estimula a organização de informações, explicação e justificativas;

$\checkmark$ Potencializa o relacionamento entre o conhecimento científico e o contexto social do estudante;

$\checkmark$ Construção da autonomia;

$\checkmark$ Prática voltada para a reflexão que parte de uma situação problema;

$\checkmark$ Participação ativa dos estudantes;

$\checkmark$ Compartilhamento de experiências e saberes;

$\checkmark$ Envolvimento perante os desafios propostos;

$\checkmark$ Desenvolvimento da leitura, da escrita e oralidade;

$\checkmark$ Desenvolve a indagação;

$\checkmark$ Necessita de tempo e planejamento;

$\checkmark$ Potencializa a interação do grupo;

$\checkmark$ Aproximação do saber científico;

$\checkmark$ Oportuniza a aprendizagem no processo de construção da AC;

$\checkmark$ Favorece a expressão oral e gestual;

$\checkmark$ Aprendizagem de forma criativa e autoral;

$\checkmark$ Relação entre a teoria e a prática, tornando-os essenciais;

$\checkmark$ Motivadores para a sala de aula;

$\checkmark$ Instiga a curiosidade, a criatividade e o desejo pela descoberta;

$\checkmark$ Estimula a interação dos pares;

$\checkmark$ Possibilita o experimentar, o levantar hipóteses e o observar;

$\checkmark$ Possibilita a presença de indicadores da AC nos estudantes;

$\checkmark$ Estimula a tomada de decisão;

$\checkmark$ Relação do experimento com o cotidiano do aluno;

$\checkmark$ Aquisição de habilidades ao realizar perguntas;

$\checkmark$ Transformação da prática pedagógica; 


\section{Desenvolvimento da autonomia e relação dialógica;}

$\checkmark$ Promove situações de aprendizagem a partir do cotidiano e da curiosidade;

$\checkmark$ Reflexão da prática em sala de aula;

$\checkmark$ Contribui para promover a pesquisa;

$\checkmark$ Possibilidade de aprimorar o processo de ensinar e aprender;

$\checkmark$ Mudança de perspectiva

Fonte: Costa; Guidotti (2020)

A contar dos aspectos emergentes, assumimos que o ensino por investigação é uma abordagem de ensino que possibilita a interdisciplinaridade e a alfabetização científica. Além disso, é uma abordagem que contribui para o desenvolvimento da criticidade, criatividade e autonomia dos estudantes. Para tanto, faz-se necessário envolver os estudantes e professores em ações de indagação, contraposição de ideias e socialização do conhecimento. Por fim, o estudo nos mostra que o ensino por investigação acontece num cenário em que professores e estudantes atuam de forma colaborativa e dialógica, relacionando os conhecimentos científicos com o contexto social, a contar de situações-problemas. Desse modo, a investigação em sala de aula oportuniza a experimentação, o levantar hipóteses e amplia novas oportunidades de pensar e agir.

\section{REFERÊNCIAS}

ARAÚJO, T. B. Aulas de Ciências: uso e desenvolvimento de sequências investigativas. 2017. 185 f. Dissertação (Mestrado) - Curso de Programa de Pós-Graduação em Ensino de Ciências Humanas, Sociais e da Natureza, Mestrado Profissional, Universidade Tecnológica Federal do Paraná, Londrina, 2017. Disponível em: http://repositorio.utfpr.edu.br/jspui/handle/1/3077. Acesso em janeiro de 2020.

AZEVEDO, L. B. S. Ensino de ciências por investigação: estudos dos conceitos básicos de eletricidade para a promoção da alfabetização científica. 2016. 142 f. Dissertação (Mestrado) Programa de Pós-Graduação em Ensino de Ciências e Matemática, Universidade Federal de Alagoas, Maceió, 2016. Disponível em: http://www.repositorio.ufal.br/handle/riufal/5483. Acesso em março de 2020.

BARCELLOS, L. S. O ensino da interação radiação-corpo humano nos anos iniciais do ensino fundamental: uma abordagem investigativa e colaborativa com enfoque ciência, tecnologia e sociedade. 2017. 125 f. Dissertação (Mestrado) - Curso de Programa de Pós-Graduação em Ensino de Física, Centro de Ciências Exatas, Universidade Federal do Espírito Santo, Vitória, 2017. Disponível em: http://repositorio.ufes.br/handle/10/6940. Acesso em março de 2020.

BAYERL, G. S. 0 ensino de ciências físicas por investigação: uma experiência nos anos iniciais do ensino fundamental. 2016. 118 f. Dissertação (Mestrado) - Curso de Programa de Pós-Graduação em Ensino na Educação Básica, Departamento de Educação e Ciências Humanas, Universidade Federal do Espírito Santo - Centro Universitário Norte do Espírito Santo, São Mateus, 2016. Disponível em: http://repositorio.ufes.br/handle/10/8422. Acesso em março de 2020.

BRITO, L. O. Ensino de ciência por investigação: uma estratégia pedagógica para promoção da alfabetização científica nos primeiros anos do ensino fundamental. 2014. 160 f. Dissertação (Mestrado) - Programa de Pós-Graduação em Ensino de Ciências e Matemática, Universidade Federal de Alagoas, Maceió, 2014. Disponível em: http://www.repositorio.ufal.br/handle/riufal/1240. Acesso em março de 2020. 
CARVALHO, A. M. Metodologia de pesquisa em ensino de física: uma proposta para estudar os processos de ensino e aprendizagem. In: ENCONTRO DE PESQUISA EM ENSINO DE FÍSICA, 9., 2004, Jaboticatubas, MG. Anais.Jaboticatubas, MG: Sociedade Brasileira de Física, 2004.

CHAGAS, H. W. K. R. S. Formação continuada de professores dos anos iniciais do ensino fundamental: uma proposta pautada em sequências de ensino por investigação. 2018. $220 \mathrm{f}$. Dissertação (Mestrado) - Programa de Pós-Graduação em Educação para Ciências e Matemática, Instituto Federal de Educação, Ciência e Tecnologia de Goiás, Jataí, 2018. Disponível em: https://www.ifg.edu.br/attachments/article/1279/Dissertacao Helainy Wanyessy Kenya Rodrigues Silva Chagas(.pdf4582kb).pdf. Acesso em janeiro de 2020.

FERREIRA, N.S.A. As pesquisas denominadas "estado da arte". Educação \& Sociedade, v. 23, no 79, p. 257-272, ago., 2002. Disponível em: https://www.scielo.br/pdf/es/v23n79/10857.pdf. Acesso em março de 2020.

GUIDOTTI, C. S. A investigação desde a sala de aula de Ciências: processo de autoformação com aperfeiçoamento teórico-prático de professores no Cirandar. Tese (Doutorado em Educação em Ciências: Química da Vida e Saúde). Universidade Federal do Rio Grande - Furg. 2019.

GUIDOTTI, C. S; HECKLER, V. Projetos investigativos desde a sala de aula. CieFi. Comunidade de Indagação em Ensino de Física Interdisciplinar. 2020. Disponível em: https://www.youtube.com/watch?v=KwvhkPok7bY\&feature=youtu.be. Acesso em abril de 2020.

GUIDOTTI, C. S; HELCKLER, V. Investigação na educação em Ciências: concepções e aspectos históricos. Revista Thema. V. 14, n. 03, p. 191-209. 2017. Disponível em: http://dx.doi.org/10.15536/thema.14.2017.191-209.545. Acesso em abril de 2020.

HILÁRIO, T; W. Vai equilibrar?: as contribuições da sequência de ensino por investigação para alfabetização em linguagem no ensino de ciências. 2018. 159 f. Dissertação (Mestrado) - Programa de Pós-Graduação em Educação para Ciências e Matemática, Instituto Federal de Educação, Ciência e Tecnologia de Goiás, Jataí, 2018. Disponível em: http://repositorio.ifg.edu.br/handle/prefix/454. Acesso em março de 2020.

ISSA, A. R. M. S. A construção da argumentação no ensino de Ciências por investigação visando a promoção da alfabetização científica. 2015. 96 f. Dissertação (Mestrado) - Programa de Pós-Graduação em Educação para Ciências e Matemática, Instituto Federal de Educação, Ciência e Tecnologia de Goiás, Jataí, 2015. Disponível em: http://repositorio.ifg.edu.br/handle/prefix/452. Acesso em março de 2020.

LEONOR, P. B. Ensino por investigação nos anos iniciais: análise de sequências didáticas de ciências sobre seres vivos na perspectiva da alfabetização científica. 2013. 192 f. Dissertação (Mestrado) - Curso de Mestrado em Educação, Instituto Federal do Espírito Santo, Vitória, 2013. Disponível em: https://repositorio.ifes.edu.br/xmlui/handle/123456789/158. Acesso em março de 2020.

LIMEIRA, J. A. R. Práticas de ensino por investigação nas aulas de Ciências desenvolvidas nos anos iniciais do ensino fundamental. 2015. 127 f. Dissertação (Mestrado) - Programa de Pós-Graduação em Formação Científica, Educacional e Tecnológica, Universidade Tecnológica Federal do Paraná, Curitiba, 2015. Disponível em: http://repositorio.utfpr.edu.br/jspui/handle/1/1590. Acesso em março de 2020.

LORENZON, M. A espiral investigativa como uma estratégia de desenvolvimento da alfabetização científica nos anos iniciais do ensino fundamental. 2018. 232 f. Dissertação (Mestrado) - Curso de Programa de Pós-Graduação em Ensino, Universidade do Vale do Taquari, Lajeado, 2018. Disponível em: http://hdl.handle.net/10737/2485. Acesso em janeiro de 2020. 
MOURA, M. B. Formação continuada de professores e a metodologia de ensino por investigação nos anos iniciais do ensino fundamental de Paraúna-Go. 2016. $120 \mathrm{f}$. Dissertação (Mestrado) - Programa de Pós-Graduação em Educação para Ciências e Matemática, Instituto Federal de Educação, Ciência e Tecnologia de Goiás, Jataí, 2016. Disponível em: https://www.ifg.edu.br/attachments/article/1279/Disserta\%C3\%A7\%C3\%A3o-

Marcelo\%20Bueno\%20Moura-2015\%20(.pdf\%201.997\%20kb).pdf. Acesso em março de 2020.

NASCIMENTO, S. S. B. "Onde está o ar?": sequência de ensino investigativo para a promoção da alfabetização científica de alunos do $3^{\circ}$ ano do ensino fundamental. 2016. 136 f. Dissertação (Mestrado) - Programa de Pós-Graduação em Educação para Ciências e Matemática, Instituto Federal de Educação, Ciência e Tecnologia de Goiás, Jataí, 2016. Disponível em: https://www.ifg.edu.br/attachments/article/1279/Dissertacao-Stephany-Siqueira-Barbosa-

Nascimento-2016-(.pdf1.873kb).pdf. Acesso em março de 2020.

OLIVEIRA, J. Q. P. Atividades experimentais: estratégia para auxiliar no ensino de ciências. 2017. 142 f. Dissertação (Doutorado) - Curso de Programa de Pós-Graduação em Ensino de Ciências Exatas, Mestrado em Ensino de Ciências Exatas, Universidade do Vale do Taquari, Lajeado, 2017. Disponível

em: https://www.univates.br/bdu/bitstream/10737/2155/1/2018JaciquaraQueirozPastanadeOliveira.pdf. Acesso em março de 2020.

REIS, L. P. O desenvolvimento da argumentação em atividades investigativas para alunos do Ensino Fundamental. 2017. 213 f. Dissertação (Mestrado) - Curso de Programa de Mestrado Profissional em Projetos Educacionais de Ciências, Escola de Engenharia de Lorena, Universidade de São Paulo, Lorena, 2017. Disponível em: https://teses.usp.br/teses/disponiveis/97/97138/tde29032017-093517/publico/PED16002 C.pdf. Acesso em janeiro de 2020.

ROMANOWSKI, J. P.; ERNS, R. T. As pesquisas denominadas do tipo "estado da arte" em educação. Curitiba: Diálogo e Educação, v.6, n.19, p.37-50, set./dez, 2006. Disponível em: http://www2.pucpr.br/reol/pb/index.php/dialogo?dd1=237\&dd99=view\&dd98=pb.

Acesso em março de 2020.

SOARES, G. F. A. Ensino de Ciências por investigação: um desafio à formação dos professores dos anos escolares iniciais. 2017. 88 f. Dissertação (Mestrado) - Curso de Programa de Pós-Graduação em Docência em Educação em Ciências e Matemáticas - Mestrado Profissional, Universidade Federal do Pará - Instituto de Educação Matemática e Científica, Belém, 2017. Disponível em: http://repositorio.ufpa.br/jspui/handle/2011/10523. Acesso em março de 2020.

SPERANDIO, M. R. C. Ensino de Ciências por investigação para professores da educação básica: dificuldades e experiências de sucesso em oficinas pedagógicas. 2017. 239 f. Dissertação (Mestrado) - Curso de Programa de Pós-Graduação em Ensino de Ciências Humanas, Sociais e da Natureza, Universidade Tecnológica Federal do Paraná, Londrina, 2017. Disponível em: http://repositorio.utfpr.edu.br/jspui/handle/1/3017. Acesso em março de 2020.

ZERLOTTINI, K. G. Ensino de ciências por investigação e produção de textos: um diálogo possível para a construção da autonomia de alunos das séries iniciais. 2017. 242 f. Dissertação (Mestrado) - Curso de Mestrado Profissional em Educação e Docência, Faculdade de Educação, Universidade Federal de Minas Gerais, Belo Horizonte, 2017. Disponível em: http://hdl.handle.net/1843/BUOS-B2YMNY. Acesso em janeiro de 2020.

Submissão: 29/10/2020

Aceito: 03/12/2020 